\title{
UMA EXPERIÊNCIA DE EDUCAÇÃO HÍBRIDA NO INTERIOR DA AMAZONIAE ENTRE PRÁTICAS, APRENDIZAGENS E CONTRADIÇÕEs
}

A BLENDED-LEARNING EXPERIENCE IN THE INTERIOR OF THE AMAZON: PRACTICES, LEARNING AND INCONSISTENCIES

\section{Raquel Lopes}

Doutora em Ciências Sociais/Antropologia pela Universidade Federal do Pará (Altamira/Brasil).

E-mail: ralopes@ufpa.br

\section{Leonardo Zenha Cordeiro}

Doutor em Políticas Públicas e Formação Humana na Universidade Estadual do Rio de Janeiro (Rio de Janeiro/Brasil).

Professor na Universidade Federal do Pará (Altamira/Brasil).

E-mail: leozenha@gmail.com 


\section{RESUMO}

O trabalho traz o registro de uma experiência de educação híbrida no interior da Amazônia brasileira, o Curso de Especialização em Educação por Inversão Pedagógica: Inclusão para a Emancipação em Territórios Socioeducativos na Transamazônica-Xingu, do Campus de Altamira, da Universidade Federal do Pará, analisando as potencialidades de inovação da proposta que foi desenvolvida com diferentes sujeitos oriundos de diferentes contextos, tais como ribeirinhos, camponeses, extrativistas, indígenas e urbanos, por meio de múltiplas formas de aprendizagem possibilitadas por diferentes metodologias, como a sala de aula invertida, a educação online, EaD e a pedagogia da alternância. A proposta teve como pano de fundo a democratização do acesso à educação formal e a convicção da educação como modo de modificar a vida das pessoas. A metodologia utilizada para a produção de dados deste artigo envolveu imersão direta na realidade investigada, uso de um formulário, entrevistas e o acompanhamento do curso nos seus 18 meses de duração. Os resultados indicam possiveis mudanças que o acesso à educação proporciona aos estudantes e consequentemente aos seus territórios de origem. Esses resultados podem ser vistos tanto pelo movimento dos estudantes ao longo de seu percurso de formação quanto pelos "produtos" apresentados como trabalhos finais de curso/TCC, que demonstram apropriação dos principais eixos do debate teórico-epistemológico realizado, assim como compreensão das implicações políticas para os coletivos de que fazem parte.

Palavras-chave: Inversão Pedagógica. Educação híbrida. Territórios Socioeducativos.

\section{ABSTRACT}

This research presents a blended-learning education experience in the Brazilian Amazon interior, as part of the post-graduation program research in Education entitled: "Flipped-classroom: Inclusion for Emancipation in Socio-Educational Territories in Transamazon-Xingu ", from Federal University of Pará - Altamira Campus, analyzing the potential innovation of projects developed with different subjects from different contexts, such as river community people, farmers, extractivists, indigenous and urban people, through multiple forms of learning made possible by different methodologies, such as the flippped-classroom, online education, distance education and alternative pedagogy. The inicial proposal holds the backdrop the democratization access as a way of formal education and the conviction of education as a way of changing people's lives. The methodology used for the data collection of the data analyzed in this article involved direct immersion in the investigated reality, with interviews and monitoring of the course for a period of 18 months. The results indicate possible changes in the students' lives and consequently to their territories of origin when they have access to education. These results can be categorized both by the movement of students along their training path and by the 'products' presented as final course research, which demonstrate appropriation of the main axes of the theoretical-epistemological debate carried out, as well as their political implications. For the collectives of which they are part, which leads us to affirm that the experience provided new practices and new learning.

Keywords: Flipped-classroom. Blended-learning. Socio-educational territories. 


\section{INTRODUÇão}

Neste trabalho apresentamos algumas evidências preliminares do potencial de uma experiência de educação híbrida vivenciada no Campus de Altamira, uma unidade avançada da Universidade Federal do Pará, localizada na região da Transamazônica, no oeste paraense. Trata-se de um curso de pósgraduação lato sensu ao qual demos o ambicioso nome de ESPECIALIZAÇÃO EM EDUCAÇÃO POR INVERSÃO PEDAGÓGICA: INCLUSÃO PARA A EMANCIPAÇÃO EM TERRITÓRIOS SOCIOEDUCATIVOS NA TRANSAMAZÔNICA$X I N G U$, pelo qual buscamos alcançar diferentes trabalhadores em educação que, por causa de suas condições de vida e trabalho, não podiam frequentar a universidade nos períodos regulares de oferta de cursos.

Antes de apresentarmos o curso, precisamos dizer que desde o início de sua proposição houve uma série de reações e questionamentos colocando em xeque a possibilidade mesma de sua implementação: ouvimos diversos comentários, ora mais ora menos assertivos, a respeito da exequibilidade da proposta, de sua "seriedade" como pós-graduação, da legitimidade acadêmico-científica de seus fundamentos teórico-metodológicos, enfim... Foi apenas depois de todo um processo de convencimento, baseado em sessões de estudo, sugestões de leituras e indicação de materiais referentes a experiências de outras universidades mais 'centrais' (ou menos 'periféricas') que parte da própria equipe e de sujeitos em cargo de gestão no Campus se predispuseram a analisar a proposta e encaminhar os procedimentos para sua aprovação nas devidas instâncias da engrenagem administrativa da universidade.

Essa ressalva inicial é necessária para entendermos uma série de aparentes contradições que vão aparecer quando apresentarmos os resultados advindos da percepção de docentes e discentes: em muitos casos, ficará claro que essa percepção da educação híbrida foi apenas parcial, dado que a compreensão manifesta no plano discursivo não se materializou no plano da prática ao longo do percurso de formação, que foi de dezoito meses (contando-se apenas o período de efetivação do curso a partir da sua aprovação pelo Conselho Superior da UFPA, em Belém.

Assim, este texto traz o relato da nossa experiência de educação híbrida, em nível de pós-graduação lato sensu, evidenciando e analisando seu potencial de inovação como 'tecnologia educacional' no contexto local do Campus de Altamira, mas problematizando também seus limites como prática educativa, pois acreditamos que como sujeitos históricos estamos imersos na contradição inerente à ação humana e não podemos simplesmente ignorar os problemas nem tampouco fugir da tensão provocada por eles: assumir nossa incompletude é condição para avançar; apenas reconhecendo erros no percurso é possível se responsabilizar por eles e realinhar táticas e estratégias para corrigi-los e otimizar o resultado de nossa 
ação no sentido de alcançar os propósitos de toda prática educativa: buscar a emancipação humana e lutar contra toda forma de desigualdade.

Sabemos que a potencialidade desse propósito não se esgota em ações pontuais de formação, independentemente de seu formato, mas a experiência aqui relatada evidencia que ela pode se concretizar como práxis educativa contribuindo concretamente para mudar realidades pessoais e coletivas no chão da vida real e nos limites do tempo histórico em que se efetiva, esgarçando as bordas do sistema escolar/ universitário e chegando a coletivos de outra forma excluídos da educação formal, se a assumimos como concepção e como prática. É, então, nesta perspectiva que compartilhamos parte de nossas aprendizagens com educação híbrida, esperando contribuir para esse debate.

0 texto que se segue está organizado em seções para facilitar a leitura, bem mais do que para delimitar seu conteúdo. Assim, trazemos inicialmente uma breve contextualização do curso de Especialização em Educação por Inversão Pedagógica; em seguida apresentamos de forma mais detalhada a ideia de metodologia híbrida em torno da qual o curso foi concebido; posteriormente propomos a análise de alguns resultados alcançados evidenciando seu potencial de sucesso e inovação, mas problematizando, na mesma medida, as contradições enfrentadas e assumindo/reconhecendo os limites de nossa ação, não para a eles nos curvarmos resignados, mas para aprendermos com a realidade e com os sujeitos envolvidos no processo o que ainda precisamos conhecer para sermos mais efetivos em nossas práticas.

\section{SOBRE O CONTEXTO DA EXPERIÊNCIA}

A proposta Curso de Especialização em Educação por Inversão Pedagógica aqui apresentada foi concebida com o propósito de ser espaço privilegiado de formação teórico-metodológica inovadora e efetiva com trabalhadores da educação básica e demais sujeitos envolvidos com a escola no território da Transamazônica-Xingu, por meio da reflexão radical sobre a função da educação escolar na constituição do tecido social desse território, tendo em vista as múltiplas faces de sua sociodiversidade. Sua concepção, portanto, foi diretamente relacionada à dupla e premente necessidade de ressignificar as diferentes experiências socioeducativas aí presentes e criar situações efetivas de aprendizagem profissional em contextos educativos formais, informais e não formais (GOHN 2006).

Essa proposição teve como parâmetro de relevância para oferta a situação de sujeitos ligados a escolas localizadas em áreas remotas e de difícil acesso, como aldeias indígenas, quilombos, reservas extrativistas, assentamentos de reforma agrária e áreas ribeirinhas. Por suas características peculiares, que vão além da dificuldade de acesso, estas escolas e seus contextos trazem muitos desafios, particularmente no que diz respeito aos fundamentos epistemológicos da atuação docente, uma vez 
que requerem dos professores aí envolvidos, para além da competência técnica em sua respectiva área de conhecimento, uma compreensão teórico-epistemológica consistente e sensível às especificidades locais.

Via de regra, as populações dessas áreas estiveram ao longo de sua história completamente invisibilizadas pelo Estado brasileiro. No caso das reservas extrativistas do município de Altamira-Pará, a implantação e o funcionamento de escolas da rede municipal, a partir do ano de 2008, têm sido marcados por múltiplas ambivalências, colocando em questão, por vezes de forma muito crua, o propósito mesmo da oferta de educação escolar: seria esta um direito ou a imposição de um projeto colonizador a fragilizar ainda mais o já sensível tecido social local?

No que concerne aos educadores em exercício nas escolas destas áreas, as condições materiais dificultam muito o acesso a processos de formação continuada, especialmente no formato de curso presencial, uma vez que os constantes deslocamentos e a permanência por longos períodos nas áreas inviabilizam sua presença física em tais cursos. Embora este seja, de fato, um fator de dificuldade para o envolvimento de educadores em processos de formação continuada, geralmente ofertados no Campus Universitário na cidade, sentimos que havia outros fatores igualmente ou até mais problemáticos que comprometiam o êxito dos cursos de formação continuada ofertados; um desses fatores está muito relacionado ao formato e à concepção metodológica de muitas dessas iniciativas, que continuam estruturadas pelo modelo "industrial" de educação: a sala de aula governada por um professor detentor do saber proferindo o conhecimento a alunos passivos que o recebem em pacotes (para logo depois o 'esquecerem'). Nesse formato, a formação, ainda que de boa qualidade acadêmica, não repercute, não tem ressonância na prática docente dos alunos-professores que, quando conseguem acessar tais oportunidades, voltam delas ainda mais extenuados e menos conectados com o chão de seus espaços de atuação.

São comuns e recorrentes depoimentos desses sujeitos, tanto durante os cursos de formação continuada quanto uma vez deles egressos, expressando seu estado de desconforto com a profissão docente e, de certo modo, denunciando uma situação de mal estar, de incômodo e desânimo relativamente à distância entre os desafios de sua vivência profissional, suas expectativas de aprendizagem e aquilo que, de fato, obtiveram da universidade: há pouca conexão entre o que se discute enquanto teoria no espaço acadêmico e os desafios enfrentados cotidianamente no chão da escola.

É muito provável que parte significativa dessa situação se deva ao fato de os pilares da formação docente, seja nas Licenciaturas, seja nos Cursos de pós-graduação lato (Especialização) ou stricto sensu (mestrados profissional e acadêmico ou doutorado), ainda estarem centrados no paradigma da razão 
instrumental, de acordo com o qual se pensa a formação PARA e não COM os sujeitos e sempre a partir de uma olhar externo aos territórios educativos em que estes atuam. A própria matriz de formação que hoje prevalece em nossos centros de formação universitária não dialoga com a realidade das escolas; quando o faz, é sempre a posteriori, como uma espécie de apêndice ou de 'mal necessário' por ocasião da pesquisa de campo para a elaboração de trabalho final que, via de regra, serve apenas para constatar o fracasso da escola, sem devolutiva de resultados, sem restituição de aprendizagens, sem acúmulos experienciais para os "pesquisados".

Alterar um tal estado de coisas, ou ao menos tentar, exige um posicionamento teórico-epistemológico distinto. Exige uma coragem para fazer algo em outra direção, que garanta mais organicidade, mais conexão entre as experiências de formação e as realidades dos territórios educativos em que os trabalhadores em educação atuam, de modo a se forjar novas práticas, novas possibilidades de enfrentamento das questões que nos atingem a todos, mas, em especial, às minorias historicamente alijadas do usufruto de bens e direitos sociais básicos.

Foi, então, nessa perspectiva que se efetivou a proposta de Curso de Especialização em Educação por Inversão Pedagógica objetivando garantir formação docente compatível com os desafios colocados pela conjuntura acima apresentada, pois, como já referido, a complexidade do contexto de atuação docente reclama processos formativos específicos, em consonância com as necessidades vivenciadas no chão das escolas locais, no interior da floresta amazônica, com suas contradições, desafios e potencialidades - que vão desde a questão de insegurança fundiária, passando pelos tensionamentos decorrentes da implantação de mega projetos de desenvolvimento, como a Usina Hidrelétrica de Belo Monte, até as peculiaridades socioantropológicas das populações residentes.

A ideia, em linhas gerais e conforme aponta M. Arroyo (2017), foi formar educadores sensíveis e comprometidos com uma educação humanizadora, porque vinculada às identidades, aos sofrimentos e aos projetos de vida de seus educandos, assim como às questões mais gerais dos territórios socioeducativos em que vivem. Para que o direito à educação se efetive em práticas humanizadoras, os docentes precisam estar conectados com os anseios de seus discentes, suas angústias, seus medos e desejos, com seus projetos de vida.

Essa foi a matriz de formação proposta pelo Curso de Especialização em questão - em permanente diálogo com a cultura, as tecnologias de informação e comunicação e a construção de uma escola verdadeiramente popular, conectada com a vida. Para que isso fosse efetivado, foi desenvolvida uma metodologia que colocava o cotidiano dos sujeitos, as angústias e inquietudes vivenciadas nos seus 
territórios em evidência e como matéria-prima da proposta curricular, por meio de diferentes abordagens no processo de aprendizagem que relatamos a seguir.

\section{SOBRE A METODOLOGIA DO CURSO: HIBRIDISMO \& HETERODOXIA}

A metodologia praticada durante o curso teve como perspectiva filosófico-conceitual a abordagem multireferencial (ARDOINO, 1998; MACEDO, 1998), percebendo o território e seus sujeitos de maneira heterogênea e plural e, ao mesmo tempo, idiossincrática. Nesse sentido, a proposta partiu de uma multiplicidade de conceitos e métodos envolvendo a valorização das culturas e dos saberes-fazeres (ALVES, 2003; FERRAÇO, 2007) desses sujeitos no cotidiano de vida (CERTEAU, 2009) e na potencialização de seus modos de existência e resistência, valorizando os coletivos e os processos identitários. Assim, apontamos como eixo central os modos de fazer e de criar conhecimento no cotidiano, diferentes daquele aprendido, na modernidade, especialmente, e não só, com a ciência. Desse modo, as indagações que moveram as ações sempre tinham como questões mobilizadoras: como acontece o fazer cotidiano dos sujeitos envolvidos no Curso, em suas realidades, seus modos de vidas, de relações sociais, de produção de culturas e conhecimentos tradicionais? Quais e como são as relações com a natureza na transformação dos seus espaços físicos e nos modos de vida? Que inquietudes essas realidades da vida trazem para a escola e que implicações têm para o trabalho docente? Como a escola reage a essas demandas? Que conhecimentos são 'metabolizados' no corpo-escola para a sua manutenção em cada território socioeducativo? De que saberes-fazeres dispõem os educadores para existirem como sujeitos sociais em tais contextos? De que conhecimentos necessitam? 0 currículo praticado atualmente dialoga com a vida? Em que medida?

Considerando tais questões, a formação foi alicerçada na possibilidade de inversão da centralidade pedagógica, deslocada da universidade para os territórios que foram denominados nesse Curso como "territórios educativos". Essa perspectiva não cabia no formato de oferta até então praticado pela universidade (cursos presenciais ou cursos a distância), por isso tomamos a iniciativa de aliar: 1) o atendimento às demandas que nos chegavam desses territórios pelas vozes dos seus sujeitos; 2 ) seu potencial de produção de conhecimentos; e 3) aquilo que sabíamos fazer como professores-pesquisadores implicados na realidade educacional em que atuávamos. Essa tríplice configuração de cenário nos levou a uma busca igualmente tripartida de enfrentamento em que associamos elementos da pedagogia da alternância (GIMONET, 2007), da sala de aula invertida (VALENTE, 2014) e do método da cartografia (PASSOS; KASTRUP; ESCÓSSIA, 2009). 
Superados os percalços iniciais de apreciação e aprovação da proposta pedagógica do curso nas instâncias devidas, tivemos sua regulamentação no âmbito do Conselho Superior de Ensino e Pesquisa da UFPA por meio da Portaria N 5.070, de 23 de agosto de 2018. Ao longo do mês de setembro foi feita a divulgação do curso e a mobilização junto a secretarias municipais de educação e organizações de classe, como sindicatos de professores; em outubro foi realizado o processo de seleção dos candidatos e em novembro tivemos o primeiro encontro presencial entre professores, estudantes e colaboradores, a que chamamos de $1^{\circ}$ Seminário de Tempo-Universidade.

Foram planejados três encontros presenciais: este primeiro que ocorreu em novembro de 2018; 0 segundo, em fevereiro de 2019; e o terceiro, em julho de 2019. Estes momentos presenciais (Seminários de Tempo-Universidade) foram intercalados com atividades a serem realizadas nas comunidades de pertencimento dos estudantes (Seminários de Tempo-Comunidade), pelas quais estes sujeitos fariam uma imersão reorientada na multiplicidade dos modos de vida existentes em seus territórios e cujos resultados seriam compartilhados no Seminário de Tempo-Universidade seguinte.

Para que isso se efetivasse, no primeiro momento os estudantes trariam uma descrição da relação com seus territórios, os desafios a serem enfrentados e questões sobre como o curso poderia potencializar não apenas novas compreensões da realidade, mas sobretudo, novas "maneiras de fazer", de intervir no enfrentamento das situações consideradas sensiveis e problemáticas.

Nos momentos iniciais de "colocação em comum", quando os estudantes compartilhariam suas inquietudes e apresentariam os resultados de suas atividades de Tempo-Comunidade, todos os docentes responsáveis pelos componentes curriculares previstos para aquele bloco deveriam estar presentes para realizar uma "escuta ativa" e desse processo dialógico extraírem os elementos a serem tratados em cada eixo de trabalho conforme sua área de conhecimento, cujo debate ocorreria em seguida em formato de aula ou de oficina. Estas atividades, as oficinas, poderiam ter um caráter de cadeira "obrigatória" ou "optativa" conforme os temas de pesquisa/trabalho de cada estudante que, em atenção aos objetivos do curso, deveriam estar vinculados aos seus territórios de pertencimento.

Assim, as referências metodológicas da sala de aula invertida com sua "pedagogia ativa", estiveram em estreito diálogo com a pedagogia da alternância, acima descrita. É importante ressaltar que esse acúmulo, especialmente no que concerne à pedagogia de alternância e suas potencialidades de inovação, já vem sendo posto a prova nos cursos de educação do campo em todo o país .Em um artigo recente sobre o ensino de ciências na Licenciatura em Educação do Campo da UFPA/Campus de Altamira, percebemos que a integração do Tempo-Universidade com o Tempo-Comunidade é um movimento fecundo para processos inovadores. Essa interação entre práticas educativas de alternância com usos 
formais e informais das TICs "[...] pode trazer elementos que contribuem para novas aprendizagens e novas inventividades [...]" (CORDEIRO; CORREA; FORMIGOSA, 2019, p.12), conferindo uma radicalidade maior em termos de potencial educativo.

Por isso o design do curso de especialização em Educação por Inversão Pedagógica iniciou-se e terminou tendo como referências os territórios educativos a que sujeitos do curso estavam vinculados o que trouxe diversos elementos e características diferentes desses territórios, que ficaram mais nítidos nos trabalho finais defendidos pelos estudantes (que vamos especificar mais à frente).

Durante esse processo, nos três encontros presenciais (Tempos-Universidade), foram ofertadas diferentes atividades curriculares em formato de aulas, oficinas, palestras e trabalhos individuais e coletivos. Durante os Tempos-Comunidade, foram possibilitadas diversas atividades em AVA's, orientadas tanto por professores do curso, quanto pela coordenação pedagógica e estagiários - num processo ininterrupto de alimentação e retroalimentação dos temas em debate no curso.

Outro diferencial metodológico que consideramos de forte potencial inovador, e também estreitamente vinculado seja à pedagogia da alternância, seja à sala de aula invertida, foi a abordagem proposta pelo método da cartografia, cuja principal contribuição se fez sentir na proposição trazida por Passos e Alvarez no texto "Cartografar é habitar um território existencial" (PASSOS; ALVAREZ, 2009, p. 131-149). Essa perspectiva de análise contribuiu verdadeiramente para aprofundar as reflexões sobre os desafios da pesquisa em cada território. A cartografia clássica entende essa ciência como uma representação em plantas rasas dos aspectos físicos de um determinado território.

Em sua abordagem, Passos e Alvarez convidam a relativizar essa acepção, ampliando as concepções da ciência cartográfica para um gesto relacional entre o meio, alteridade e subjetividade, superando a perspectiva da "pesquisa sobre" e assumindo o desafio existencial da "pesquisa com". A proposição desse exercício de deslocamento trouxe resultados ambivalentes: ao mesmo tempo em que provocou inseguranças, gerou também processos de trocas muito interessantes, dos quais participaram interlocutores muito expressivos, como José Manuel Moran (USP), Miguel Arroyo (UFMG), Salomão Hage (UFPA) - estes dois últimos de forma presencial, proferindo conferências, oficinas/aulas e orientação de trabalhos. Consideramos como processos bastante inovadores todas essas redes de trocas possibilitadas pelo curso, especialmente em se tratando de estudantes oriundos de povos historicamente excluídos de políticas de formação inicial e continuada; ter esse acesso a professores de diferentes Universidades Públicas com vasta produção de pesquisas em diferentes áreas trouxe também outras aprendizagens e novas oportunidades de ampliação de horizontes para todos os envolvidos - o que levou M. Arroyo a reconhecer na conferência de abertura da $1^{\text {a }}$ Jornada de Etnodiversidade, evento realizado durante 
o terceiro Tempo-Universidade do curso, em julho de 2019, que os amazônidas estão no coração da possibilidade de mudanças, que a Amazônia e seus povos devem ensinar o Brasil a fazer educação transformadora.

\section{UM EXERCÍCIO DE ANÁLISE DAS INOVAÇÕES CONQUISTADAS PELA INVERSÃO PEDAGÓGICA}

\subsection{EVIDÊNCIAS DE NOVAS APRENDIZAGENS: TRABALHOS FINAIS DE CURSO}

Pensando sobre o prisma da sala de aula invertida começamos esse exercício de análise fazendo um rápido exame das diferentes propostas de trabalhos finais apresentados pelos concluintes do Curso de Especialização em Educação por Inversão Pedagógica aqui focado, visando evidenciar elementos das inovações possibilitadas pela perspectiva da educação híbrida. Diferentemente dos demais cursos de Especialização já realizados no Campus de Altamira, este que ora discutimos previa em sua proposta pedagógica uma margem considerável de "porosidade" curricular que garantisse ao percurso formativo dos estudantes o grau de flexibilização necessário à articulação entre diferentes saberes, de modo a se concretizarem as trocas desejadas como eixo central de aprendizagens.

Sendo flexível e aberto o percurso da formação, vista como processo sempre em devir, não poderia deixar de sê-lo o momento de fechamento, de conclusão das atividades. Assim, foram previstas diferentes possibilidades de formatos para elaboração e apresentação dos trabalhos finais de curso, desde as mais clássicas, como monografia ou artigo científico, passando pela ideia de "produtos" ou "coisas", tais como mostras fotográficas, vídeos-documentários, curadorias, entre outros. As exigências formais/institucionais diziam respeito apenas à autoria e ao caráter inédito do trabalho.

Os processos de escolha do tema/objeto de estudo, da pesquisa e da construção dos "dispositivos" foram iniciados desde o primeiro encontro presencial, ainda em novembro de 2018, por meio de um conjunto de ações continuadas visando ao amadurecimento dos estudantes, a sua familiarização com possíveis orientadores e, sobretudo, seu crescimento como sujeitos de conhecimentos, vinculados afetiva e materialmente a seus territórios de pertencimento, uma vez que buscávamos concretizar a ideia central da cartografia proposta por Passos e Alvarez (2009) de "pesquisa com", isto é, a pesquisa implicada na vida, sensivel aos traços da realidade, "habitada"

Assumimos a ideia de "dispositivos" como defendida por Santos e Weber (2015), para quem tratase de coisas "que são inventadas e acionadas para lidar com as situações do cotidiano e se constituem como processos fecundos de aprendizagens. Para essas autoras, que vão ao encontro das ideias de Ardoino (2003) no contexto da pesquisa/formação multirreferencial, esses dispositivos não são meras 
ferramentas mas potencialidades que fazem emergir registros, reflexões, práticas recombinadas de narrativas e vivências nas experiências de diferentes sujeitos em seus contextos.

Dentre os trabalhos apresentados, todos conseguiram fazer uma correlação com seus territórios, com diferentes graus de intensidade, referenciando a heterogeneidade do real vivido, trazendo suas dores e inquietudes. Conforme se pode perceber pelo gráfico a seguir, houve uma preponderância entre os trabalhos apresentados de formatos "tradicionais", como o "artigo", seguido de outro formato esperado no contexto do ambiente acadêmico que é o "relato de experiências"; mas apareceram outros formatos como documentários ou mostra fotográfica, oficinas e fanzine.

Umas das inovações sugeridas pelas diretrizes iniciais do curso era a conexão dos temas a serem trabalhados alimentada pela inserção reorientada dos estudantes em sua realidade, fossem eles camponeses, ribeirinhos, extrativistas ou indígenas - e isso foi efetivado tanto nas pesquisas quanto nos trabalhos finais. Devemos ressaltar que, mesmo que esse pré-requisito já estivesse posto desde o início nos objetivos do curso, o que diferencia o processo vivido e nos permite afirmar que se trata de uma inovação são as formas como essa intervenção se realizou, evidenciando que os estudantes conseguiram refletir sobre seus diferentes territórios, problematizando seus contextos e intervindo aí de uma maneira propositiva e relacional.

Ressaltamos que houve casos em que os trabalhos finais foram apresentados em formato duplo: artigo e documentário. Ao avaliar tais trabalhos, seja como coordenadores do curso, seja como examinadores nas bancas de defesa, sentimos, não sem certo desconforto, que é o artigo que define a avaliação formal do trabalho, mas, quando comparado ao documentário, o texto escrito 'fica pobre', pois o vídeo tem outra linguagem, lida com elementos diferentes, mais vivos, que o texto por sua vez não tem como trazer, a exemplo da junção texto - imagem - áudio). Talvez devêssemos ter investido mais na possibilidade do hipertexto e forçado um pouco mais a estrutura universitária a reconhecer esse modelo como válido por si mesmo. Observemos o gráfico a seguir. 
Gráfico 1: Tipos de trabalhos finais apresentados

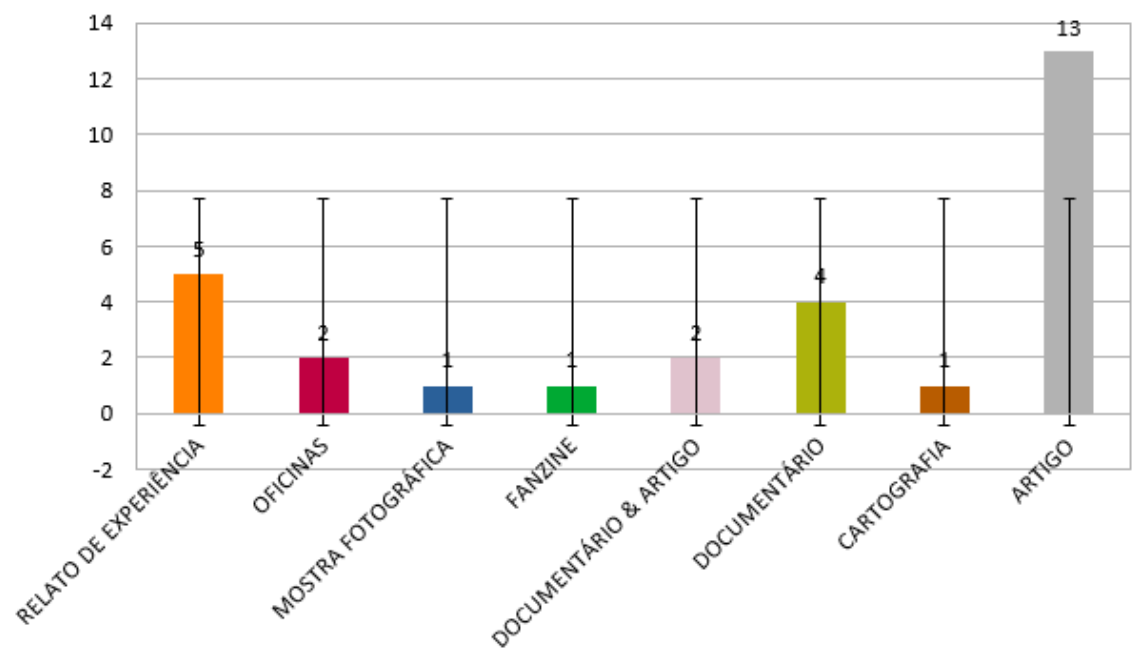

Fonte: Autores (2020)

Vemos que, ao lado do artigo, houve outros formatos de trabalho final que romperam com lógica da 'ciência positiva' ainda predominante na universidade em termos de "gênero" ou estilo de trabalho de conclusão de curso. Chama atenção o formato 'oficina', por meio do qual as autoras (uma engenheira florestal e uma educadora formada em Etnodesenvolvimento) propuseram e conseguiram promover oficinas de formação com moradores de uma área protegida visando sua preparação para o ingresso formal na rede de comercialização de móveis rústicos. Este trabalho final intitulado "Possibilidades para o fortalecimento das Oficinas Caboclas na Reserva Extrativista Riozinho do Anfrísio: aspectos histórico-organizacionais" foi o resultado do acompanhamento a um grupo de artesãos extrativistas ao longo de mais de um semestre durante o qual se exercitou uma espécie de assessoria comunitária visando à aprendizagem prática destas pessoas quanto aos meandros da cadeia de comercialização de produtos florestais, inclusive da complexa etapa de certificação. Outra iniciativa a que gostaríamos de chamar atenção é o 'fanzine': um estudante do curso, tendo trabalhado em outra reserva extrativista, com forte incidência de malária e tendo percebido dificuldades de comunicação entre os órgãos de saúde pública e os moradores em função da linguagem utilizada nos materiais informativos, propôs o trabalho intitulado "Fanzine: "Na escuta, Floresta?", incorporando elementos tanto da linguagem oral usada pelos moradores na comunicação por rádio amador, quanto o desenho e a escrita colaborativa em um dispositivo de divulgação de informações relativas à educação em saúde dentro da Reserva Extrativista 
rio Iriri, na Terra do Meio. Esse dispositivo foi testado em uma operação simulada alguns meses antes de sua apresentação no curso e evidenciou alta performance de alcance na comunidade envolvida.

Pelas limitações de espaço neste texto, não nos é possivel apresentar os demais trabalhos que consideramos inovadores mas gostaríamos de registrar que esses resultados foram alcançados muito em função do fato de que essa aproximação entre os temas escolhidos pelos estudantes e as dinâmicas de seus territórios foi um dos pontos de partida do curso, desde a aula inaugural no primeiro encontro; e foi objeto de discussão e investimento teórico-metodológico ao longo de todo o percurso de formação; daí que, metabolizados pelo currículo em ação, esses elementos da realidade foram se desenvolvendo com maior ou menor intensidade no processo e puderam ser revistos, recombinados e atualizados para a concretização dos trabalho finais.

\subsection{EVIDÊNCIAS DE NOVAS PRÁTICAS COM USO DE TIC'S: ESPAÇOS DE INTERAÇÃO PARA ALÉM DA SALA DE AULA}

Outro aspecto que consideramos relevante demonstrar como evidência de inovação vivenciada neste curso está relacionado à fomentação de novas práticas pedagógicas com auxílio de tecnologias da informação e comunicação, a exemplo de listas de transmissão, grupos de WhatsApp, encontros em ambientes virtuais de aprendizagem, entre outros.

Como já anunciado anteriormente, foram propostas diversas atividades, sendo elas presenciais, semipresenciais e a distância. Entre as primeiras, elencamos as aulas, oficinas, rodas de conversas, trocas de experiências e orientações; no segundo grupo, constam também aulas e orientações; quanto às atividades não presenciais, houve transmissões on line ao vivo, uso do ambiente Moodle com atividades assíncronas e propostas de avaliações, além de grupos de WhatsApp acompanhados pelos professores e estudantes - todas essas estratégias proporcionaram uma multiplicidade de novas experiências e práticas. Quando colocamos dessa forma parece que as dimensões existem em um fluxo predeterminado e de certo modo mecânico, em uma rigidez de protocolos a serem cumpridos de forma estanque. Mas, pelo contrário, com o decorrer do curso esse hibridismo foi sendo reformulado e reconstruído continuamente pelos participantes, inclusive com mudanças nas atividades de acordo com as necessidades e limites que iam se colocando e originavam novas demandas que requeriam de todos certa plasticidade no encaminhamento das alternativas de resolução, que foram sendo incorporadas. As Figuras 01, 02, 03 e 04, a seguir, trazem imagens desses exercícios de trabalho a distância. 


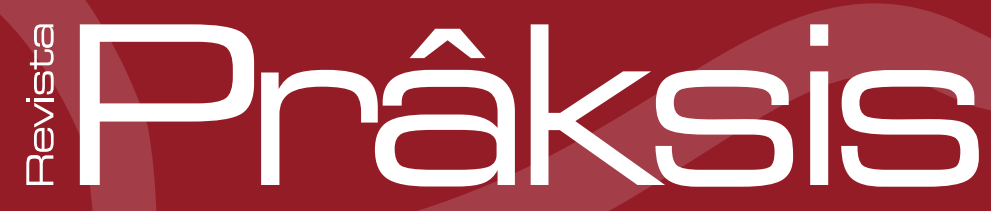

Figura 01: Uso do ambiente virtual Moodle/UFPA

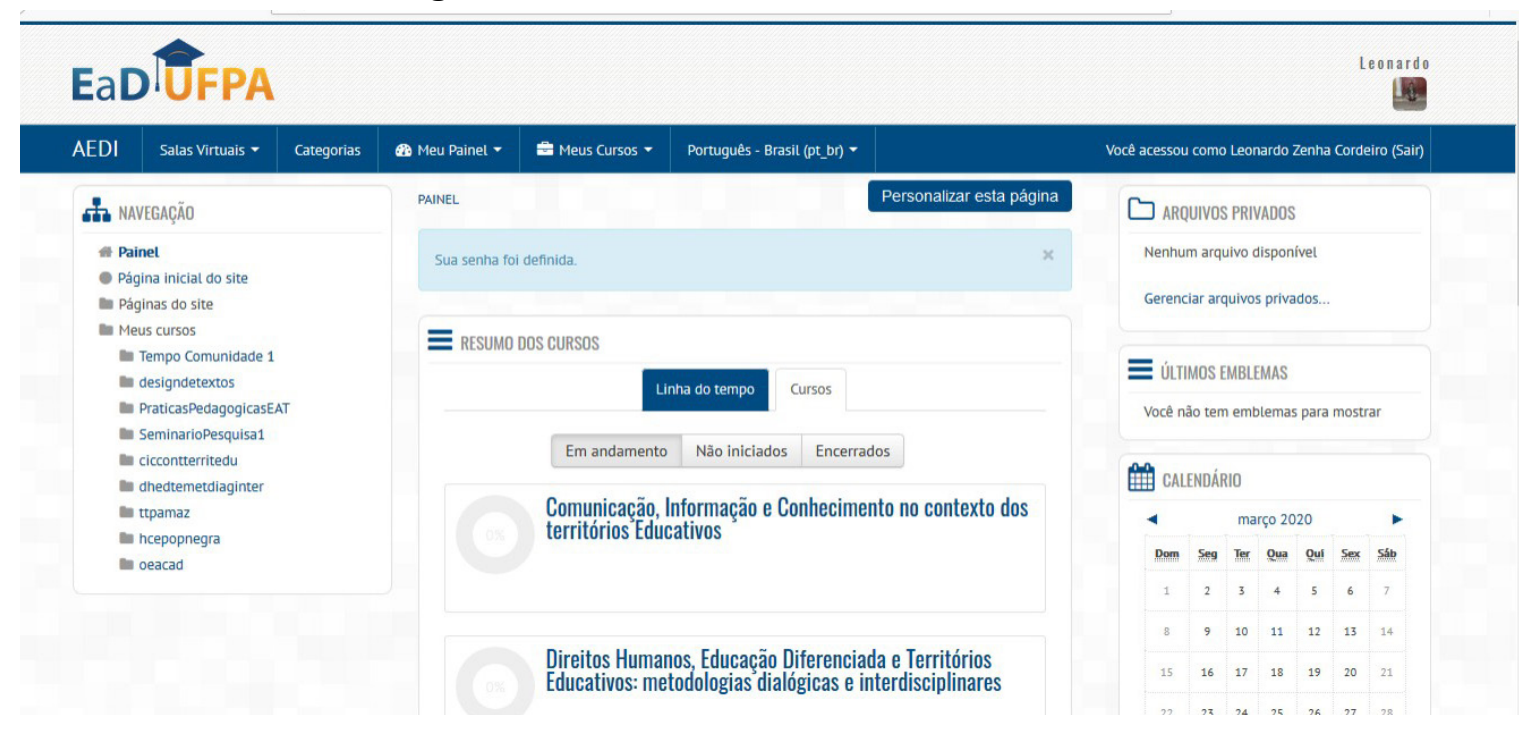

Figura 02: Uso do ambiente virtual Moodle/UFPA

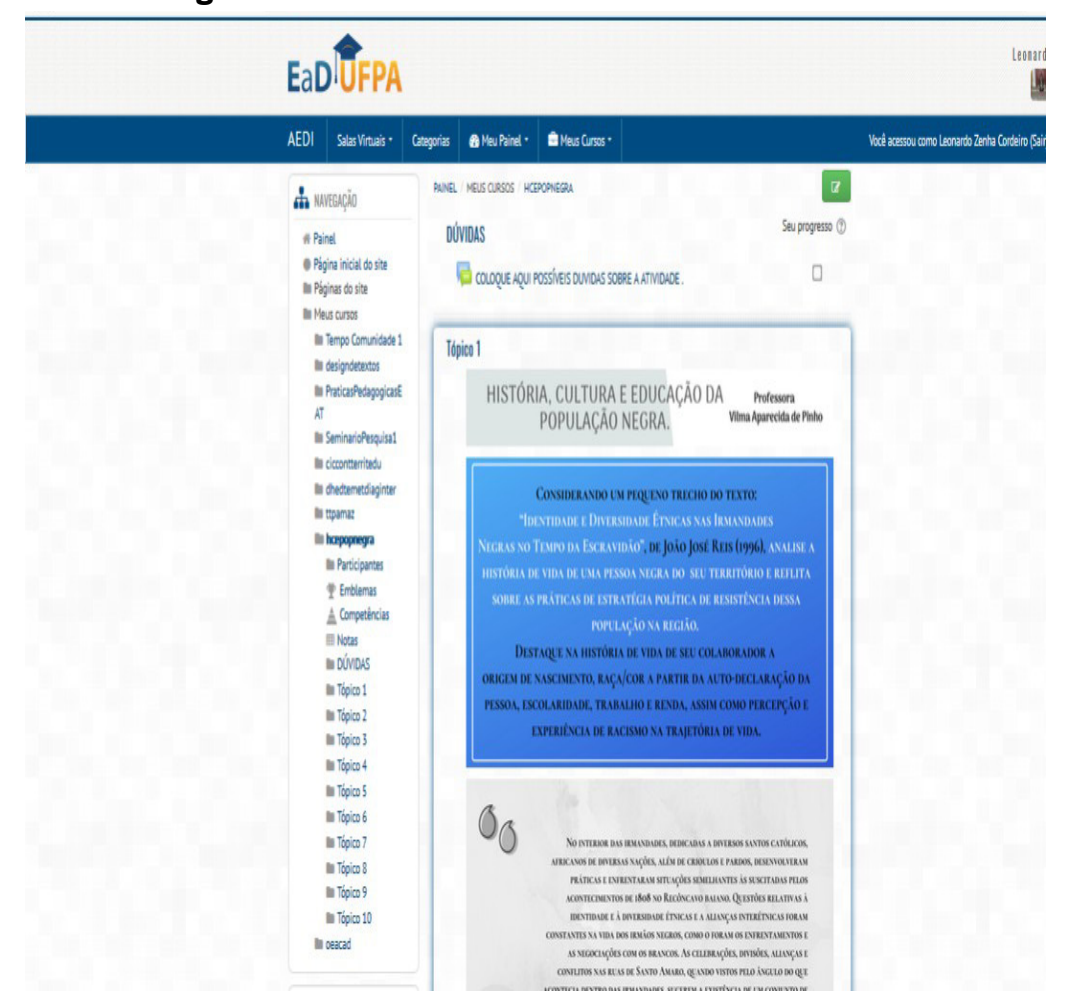




\section{Prâksis}

Figura 03: Uso do ambiente virtual Moodle/UFPA

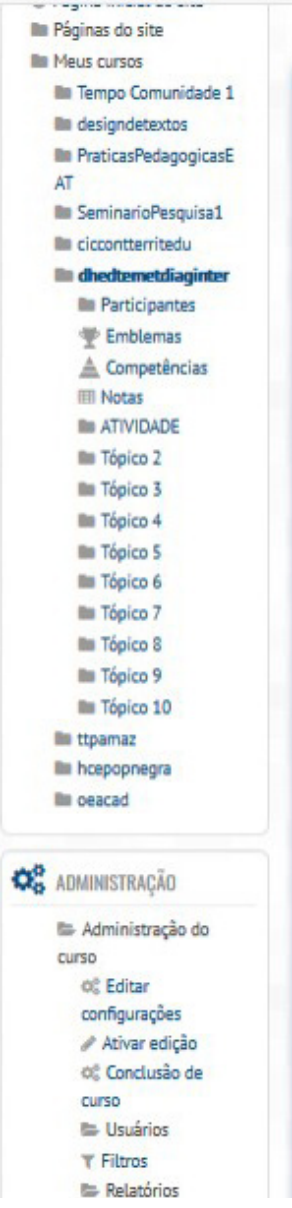

\section{ATIVIDADE}

Din Direitos Humanos, Educaçào Diferenciada e Territónios Educativos: Metodologias dialógicas e interdisciplinares

\section{METODOLOGIAS DIALÓGICAS E Professora

INTERDISCIPLINARES IItanda Miteo

Com a finalidade de conhecer e compreender o papel da sociedade civil organizada e possiveis experiências que vêm sendo desenvolvidas no ambito das comunidades, movimentos ou organizações sociais em defesa dos direitos humanos de grupos marginatizados socialmente e/ou em situação de vulnerabilidade social:

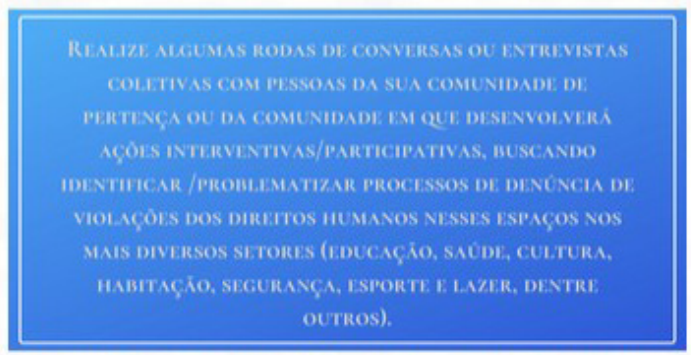

Os dados podem ser mapeados também a partir de leituras de jornais, relatórios, consultas às instituiçôes locais ou estudando documentos importantes (notícias, dossiers, dados estatisticos...) Posteriormente, sistematize e refletindo sobre as informações coletadas em um texto, destacando os seguintes aspectos:

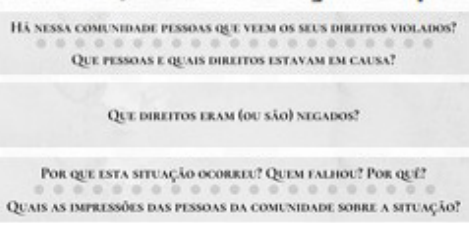

Fonte: Autores (2020) 
Figura 04: Utilização das tecnologias de Informação e Comunicação para troca de informações e processos de aprendizagem entre estudantes e professores

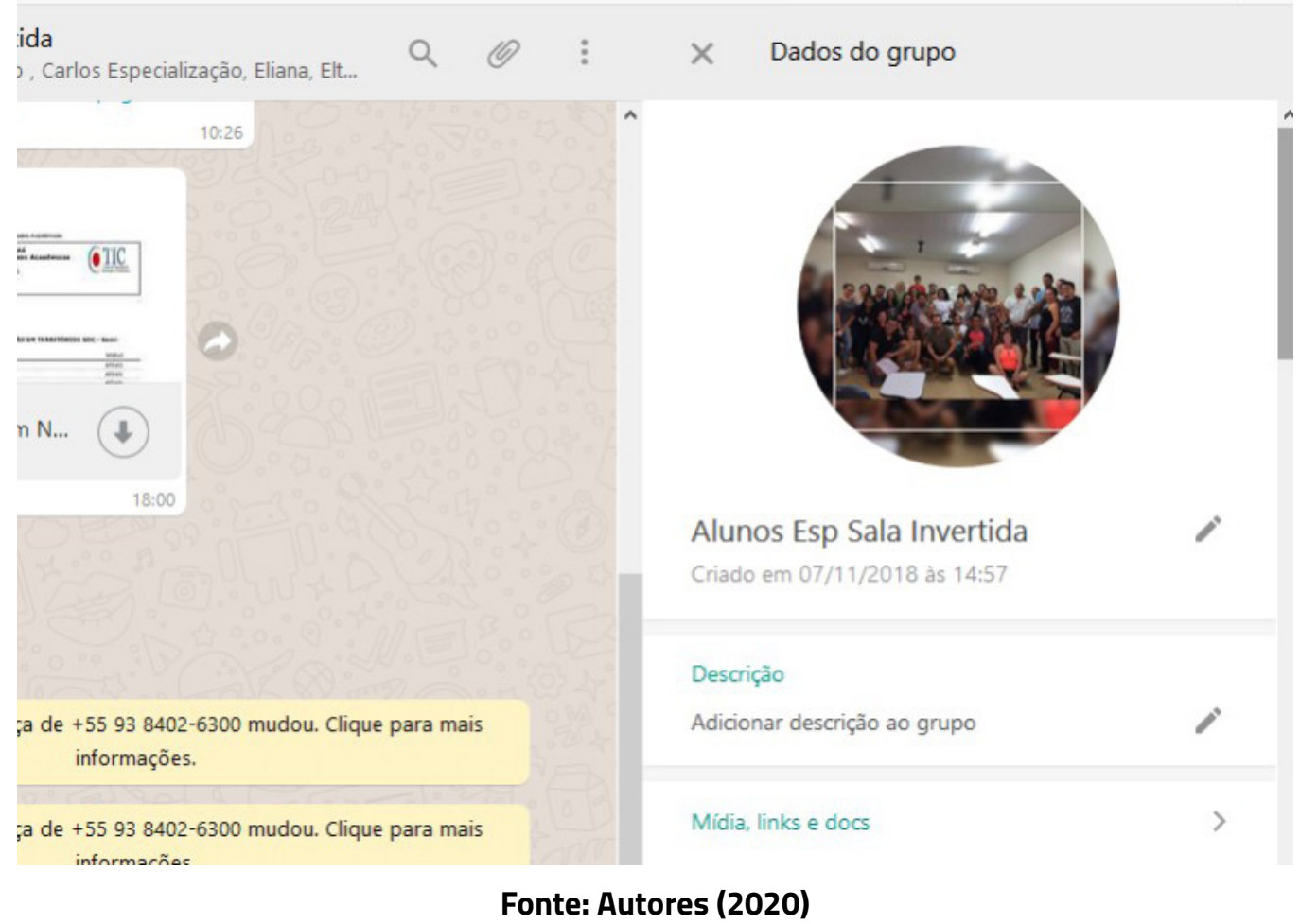

Esse "blend" de possibilidades, remixado com as identidades territoriais teve um papel central no curso, pois a realidade, em função das características desses sujeitos sociais em relação com as dinâmicas de seus territórios, requereu, inclusive, a flexibilização do rol de atividades a realizar, apontando a necessidade de suspensão ou substituição de algumas atividades. Consideramos esse momento de "renegociação" como inovação ou, também poderíamos dizer, como um processo de descolonização do saber acadêmico na tentativa dessa proposição menos rígida e mais aberta ao novo, que ainda é tabu na universidade no plano da prática - embora já não seja de todo inédito no plano retórico.

Podemos ir um pouco além e dizer que, na perspectiva amazônica, nossa experiência vai ao encontro de Felwine Sarr quando afirma que "Num contexto global de pane de projeto de civilização é preciso refundar uma nova ordem e construir sociedades que façam sentido para aqueles que as habitam. Contra a maré, lançar-se ao mar aberto" (SARR, 2019, p. 27). No contexto amazônico alguns momentos e cenários demonstram essa "pane" do atual modelo civilizatório pelas ações de desmatamento indiscriminado, garimpos e expulsão de povo originários de seus territórios pelo desenvolvimento predatório capitalista. 
Nesse sentido de "se lançar ao mar aberto contra a maré", consideramos que o conjunto dos esforços implementado no curso de Especialização em Educação por Inversão Pedagógica foi uma tentativa de criar outras possibilidades não apenas de compreender o mundo, a vida e suas relações, mas de se colocar no contexto como elementos de transformação, buscando "recriar e aperfeiçoar o mundo, sempre". Nossas tentativas configuram-se como pontos de ruptura, pois "Existe uma gênese renovada de todas as coisas. 0 eterno inacabamento das formas exige sua constante reinvenção" (SARR 2019, p. 136). Foi nesse sentido esse caminhar e continuaremos nele.

Na diversidade de propostas de trabalhos no ambiente Moodle para avaliação de desempenho discente por parte dos professores, houve a construção de pequenos ensaios ou de relatos iniciais sobre os temas de pesquisa e problematização sob a ótica da sala de aula invertida (MORAN, 2015; VALENTE, 2014) a partir das diversas experiências (BONDIA, 2002) dos estudantes para entender de onde partiam os seus interesses e como dialogavam com os contextos de suas existências e inserções profissionais e/ ou de vida. $O$ exemplo mais ilustrativo dessa prática foi o debate sobre a questão da cartografia a partir do exercício proposto no livro "Pistas do método da cartografia" (PASSOS; KASTRUP; ESCÓSSIA, 2009), particularmente a pista 7: Cartografar é habitar um território existencial (PASSOS; ALVAREZ, 2009). Deste último exercício, foi produzido por cada estudante um texto no gênero 'memorial' enfocando a relação do tema de pesquisa com seu território. A partir desse dispositivo inicial, estabeleceu-se uma perspectiva de construção coletiva e autoral sobre as identidades e suas implicações político-existenciais nos termos dos trabalhos acadêmicos a serem desenvolvidos no curso.

Neste ponto, gostaríamos de registrar que em vários componentes curriculares, foram experimentadas diferentes propostas de trabalhos avaliativos durante o curso, tais como exercícios de produções audiovisuais, deslocando um pouco a centralidade da língua escrita canônica como único objeto de avaliação de desempenho. Assim, foram produzidos programas de rádio, vídeos, entre outros dispositivos. Essas mudanças na forma de apresentar trabalhos constituem-se como um ponto fora da curva na rígida linearidade que é estabelecida no universo acadêmico de uma pós-graduação em educação.

Esse conjunto de aprendizagens e práticas inovadas e inovadoras que estruturaram a proposta do curso aqui apresentado só foi possível porque assumimos como eixo programático uma perspectiva multirreferencial, no sentido atribuído a esta palavra por Ardoino (1998), entendida como aquela força ou movimento que

[...] produz entre nós uma convocação veemente e desafiante para aprendermos a lidar com a pluralidade nas suas mais (in)tensas formas de criar a diferença, nos seus mais densos e cruéis jeitos de originar e originalizar a formação pela atualização da heterogeneidade irredutivel como modo de alter-ação. (BARBOSA; MACEDO; BORBA; BARBOSA, 2012, n. p.). 
Apesar de todo esse esforço conjunto para aprender a lidar com a pluralidade", para experimentar o novo, tanto em termos de concepções de educação, de aprendizagem e de sujeitos, e mesmo convencidos de que somente forjando o novo, aqui inclusos os dispositivos ligados às TIC's e à EaD, precisamos reconhecer os limites de nossa ação - limites que até podem ser relativizados, mas não podem ser ignorados. A próxima seção (em que trazemos alguns dados de rendimento acadêmico, assim como alguns elementos de uma avaliação realizada com estudantes e professores ao final do curso buscando captar suas representações sobre o processo vivido) é um exercício de autocrítica, nem sempre confortável, mas extremamente necessário no sentido tanto do escrutínio do nosso fazer político-pedagógico na universidade, daquele movimento difícil de olhar para o interior de nossas práticas e repensá-las, quanto de um olhar mais atento ao caráter ambivalente da universidade como instituição e como prática: de um lado, sua rigidez que engessa e desidrata ações inovadoras reafirmando um status quo institucional; de outro, a porosidade do seu tecido, pleno de interstícios, de espaços de contradição pelos quais podemos nos introduzir e espalhar feito água em cano partido.

\section{SOBRE LIMITES QUE PODEM SER SEMENTES: À GUISA DE CONCLUSÃO}

Para além de um exercício puramente protocolar de avaliação, pretendemos neste momento trazer a lume alguns elementos que evidenciam limites da nossa ação, mas que podem, também, indicar caminhos novos, seja pelo ajuste do percurso, seja pela mudança de rota. Não é possível analisarmos todos os aspectos desejados, mas vamos priorizar alguns que consideramos relevantes. Comecemos por um olhar atento ao quantum relativo ao contingente de estudantes que chegaram à reta final do curso, conforme o Gráfico 02 a seguir.

Gráfico 02: İndice de Aproveitamento

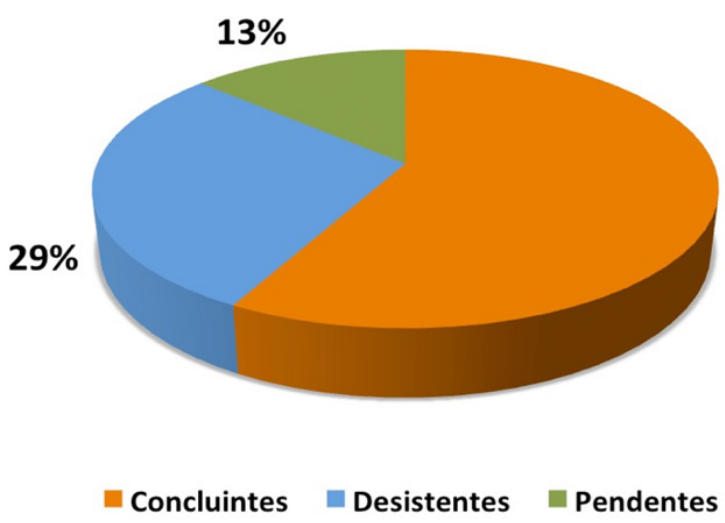

Fonte: Autores (2020) 
Dos quarenta e cinco estudantes selecionados e matriculados no Curso, no segundo semestre de 2018 , vinte e seis efetivamente concluíram o curso, o que equivale ao percentual de $58 \%$ mostrado no Gráfico acima. Este índice está muito aquém do previsto na proposta pedagógica (e do "aceitável") em cursos congêneres da UFPA, que gira em torno de $70 / \%$. O que esses dados nos dizem? 0 que significa esse índice de "insucesso" em um curso concebido justamente para democratizar o acesso de um público específico à pós-graduação na universidade pública? Trata-se de um solene fracasso de uma proposta de educação híbrida no interior da Amazônia? Foi inadequação da proposta ao contexto? Foi imperícia técnica ou política dos coordenadores? Foi falta de infraestrutura mínima na instituição ofertante? Retomaremos alguns destes pontos ao final deste texto. Refinemos o olhar, analisando com mais cuidado os dados do Gráfico 03, a seguir, referentes à identidade socioprofissional dos concluintes.

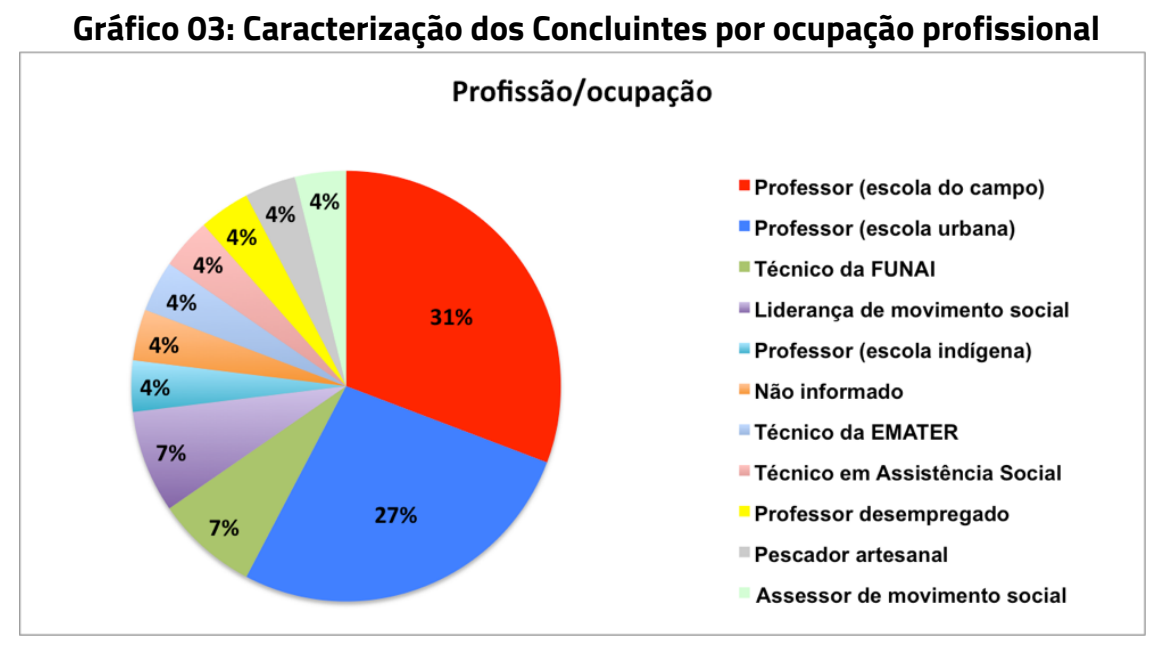

Fonte: Autores (2020)

Entre os que concluíram o curso sobressaem-se professores em exercício, seja na escola urbana, do campo, ou indígena; isso era bem previsível dado que, por se tratar de um curso de especialização em educação, visávamos alcançar este público. Ressaltamos, porém, que estes dados se referem a informações obtidas junto aos candidatos ainda durante o processo de seleção em setembro/outubro de 2018; esse cenário é muito movediço na região da Transamazônica-Xingu porque é muito elevado o número de trabalhadores em educação que não têm estabilidade no emprego. Inclusive, entre os "desistentes", há vários casos de professores desempregados que não puderam ficar no curso porque não tinham como permanecer em Altamira durante os encontros presenciais, que foram apenas três, de uma semana cada, e com certa flexibilidade, pois disponibilizamos alternativas de reposição de atividades via Moodle. Outros, pelo fato de serem contratados, tiveram que "escolher" entre manter 
o emprego ou estudar. Desses que permaneceram houve registros de imensas dificuldades para não desistir, dificuldades em grande parte de natureza econômica.

Uma primeira conclusão a que podemos chegar tem como base os depoimentos de desses estudantes concluintes sobre o resultado da experiência no curso. Para o conjunto deles, podemos assinalar como preponderantemente positiva a experiência, ainda que permeada de lacunas e de expectativas frustradas, dado que muitos esperavam um revival do modelo tradicional de pós-graduação. Alguns se ressentem de "ter tido pouca aula ao vivo", repercutindo aquela ideia antiga e 'bancária' do aluno como recebedor de informações prontas e empacotadas pelo professor; quando questionados sobre a compreensão prática de um dos pilares mais centrais da inversão pedagógica, o protagonismo do estudante como sujeito produtor de conhecimento, eles dizem ter demorado a entender isso para além da teoria e justificam sua inação, inclusive o atraso no cumprimentos das reposições de atividades nas plataformas de EaD, pela falta de hábito e de familiaridade com a metodologia. Não obstante, se considerarmos, com R. Echeverría (2016), que a aprendizagem se efetiva quando se consegue fazer algo novo que não se sabia fazer antes, ou ainda, quando se consegue fazer de forma diferente algo já sabido, podemos afirmar que houve aprendizagens, entre outros motivos, pelo fato de eles demonstrarem ter se apropriado dos eixos centrais do debate teórico-epistemológico proposto no curso - como já assinalamos na seção em que tratamos dos TCC's.

Observemos agora a configuração identitária das pessoas que não puderam continuar no curso, cuja categoria é arbitrariamente chamada de "Desistentes". Os Gráficos 04 e 05 trazem informações ligeiramente mais refinadas sobre esse grupo, filtrando traços referentes a aspectos como ocupação e auto identificação por pertencimento ao que chamamos no curso de "território educativo". Fazemos essa ressalva para lembrar que este curso de especialização fora pensado numa perspectiva de formação de sujeitos coletivos, vinculados a um "território existencial". Desde o processo seletivo, tal critério foi observado, especialmente nas entrevistas - momento em que os candidatos eram informados sobre essa perspectiva coletiva, visando à reflexão político-transformadora, e instados a se posicionar quanto a ela, dado que o sentido da proposta dificilmente se materializaria na lógica da formação individual, de base puramente cartesiana e alimentada pela ideia de meritocracia. 


\section{Gráfico 04: Caracterização dos Desistentes por ocupação profissional}

\section{Ocupação}

13 respostas

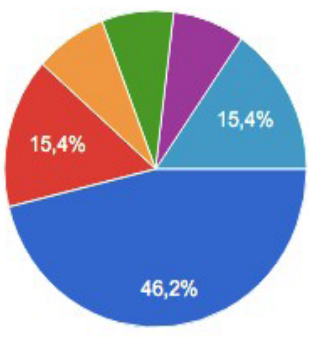

Professor da rede municipal (cidade)

- Professor da rede municipal (campo)

Professor da rede particular

Sem emprego

Prestador de serviços

Autónomo

STTR

Fonte: Autores (2020)

Gráfico 05: Caracterização dos Desistentes por auto identificação quanto ao pertencimento por território educativo

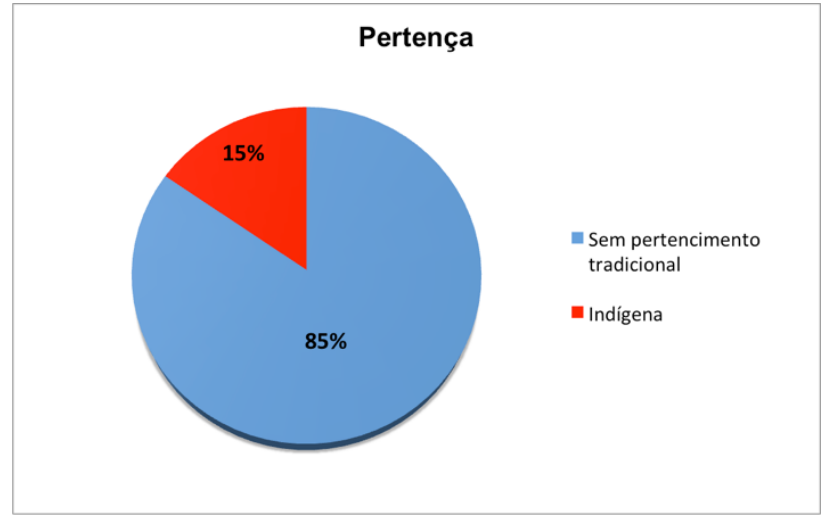

Fonte: Autores (2020)

Sabemos que, na perspectiva da educação pública, inclusiva e emancipatória, baseada em um modelo democrático de gestão, era nosso trabalho acolher a todos e garantir as condições mínimas para que, uma vez inseridos no processo, pudessem ir até o fim, integralizando os componentes curriculares e alcançando o objetivo de concluir o curso. Desse ponto de vista, temos de reconhecer que falhamos, pois olhando os dados do Gráfico 04 quanto à ocupação profissional, vemos que mais de $70 \%$ dos desistentes são professores, categoria visada pelo curso; nestes termos, teríamos desperdiçado uma oportunidade impar de contribuir na formação desses educadores. Olhando, porém, para a autoidentificação destas pessoas (Gráfico 05), temos que 85\% delas não se reconheceram como vinculada a um território educativo 
e esse fato impactou sensivelmente seu nivel de interesse e envolvimento ao longo do percurso de formação: é compreensivel que não tenham desejado continuar, uma vez que praticamente todas as atividades propostas nos diversos componentes curriculares exigiam uma postura de implicação político-existencial com algum coletivo. Esse resultado é ambivalente e nos leva a um impasse, porque temos, ainda nos dados do mesmo Gráfico 05, 15\% de indígenas, pessoas medular e reconhecidamente identificadas ao território educativo indígena, que não permaneceram no curso.

Cabe aqui uma segunda reflexão mais conclusiva a respeito do uso de dispositivos de educação híbrida na Amazônia, a partir da experiência ora relatada: como nos alerta N. Canclini (2005), o fato de vivermos em uma era marcada pelo uso da tecnologia não significa que todos têm as mesmas oportunidades de acesso aos recursos tecnológicos. Quando perguntados pelos motivos que os levaram a "desistir" de um processo de formação voltado para eles e, supostamente, facilitado pelos dispositivos de EaD, os indígenas responderam que não tinham acesso a computadores conectados à Internet que garantissem o cumprimento dos prazos estabelecidos para o retorno das atividades avaliativas do curso, quase todas elas realizadas em AVA's e de forma assíncrona. Para quase todos eles, a dificuldade de acesso à plataforma Moodle e o desconhecimento da sintaxe necessária à interação nesse dispositivo foi "xeque-mate" ou knockout. Não tivemos capilaridade suficiente para acompanhar tais situações e tentar equacionar esse problema. Partimos do pressuposto de que algumas horas de "treinamento" e algumas orientações declarativas do tipo "tutorial" dariam conta dessa demanda...

Tomando todo cuidado para não resvalarmos no discurso determinista da "carência" ou "despossessão" como explicação única para esse resultado, precisamos reconhecer que ele aponta para a necessidade de aprofundar e ampliar o debate iniciado por Arturo Escobar, ainda nos idos dos anos de 1990, e retomado por Segata e Rifiotis (2016) sobre políticas etnográficas no universo da cibercultura. Falta perguntar sobre as práticas de diferentes segmentos socioculturais no ciberespaço, falta etnografar essas práticas, de modo que possamos superar a visão ingênua e limitada das tecnologias como "ferramentas", como nos alerta N. Pretto (2008). Tecnologias não são instrumentos autônomos ou neutros, independentes e descolados das práticas de quem os produz e utiliza; ao contrário, são produtos e produtoras de culturas, de conhecimentos; estão, portanto, intrinsecamente vinculados aos seus contextos de uso, são situados.

Finalmente, uma nota breve sobre o espaço da educação híbrida na estrutura do campus onde a experiência foi vivenciada e sobre a percepção dos docentes envolvidos na proposta. Embora o blended metodológico experimentado não seja, a rigor, nenhuma novidade no cenário mais amplo da educação superior no Brasil e no mundo, em Altamira ele foi tomado com ressalvas, que oscilaram entre o desconhecimento quase absoluto de tais dispositivos, passando pela desconfiança sobre sua 
"legitimidade" e eficácia, até uma aceitação tímida da "novidade" como aposta de inovação mas com pouco envolvimento efetivo. Encerramos, por agora, essa discussão, reconhecendo que ela não se esgota aqui e reiterando que o fato de a educação híbrida ainda não ter realizado toda sua potencialidade não significa que ela não seja efetiva, mas que precisa ser contextualizada e permanentemente problematizada e problematizadora.

\section{REFERÊNCIAS}

ARDOINO, J. Abordagem multirreferencial (plural) das situações educativas e formativas. in: J. G. Barbosa (Coord.). Multirreferencialidade nas ciências e na educação (pp. 24-41). São Carlos: Editora da UFSCar, 1998.

ARDOINO, J. Para uma Pedagogia Socialista. Brasília. Editora Plano, 2003.

ALVAREZ, J.; PASSOS, E. Cartografar é habitar um território existencial. In: PASSOS, E.; KASTRUP, V.; ESCÓSSIA, L. (Orgs.). Pistas do método da cartografia: pesquisa-intervenção e produção de subjetividade. Porto Alegre: Sulina, 2009. p. 131-149.

ARROYO, M. G. Passageiros da noite. Do trabalho para a EJA, itinerários pelo direito a uma vida justa. Petrópolis: Vozes, 2017.

BARBOSA, J. G. Jacques Ardoino \& a Educação. Autêntica Editora. Edição Kindle.

BONDIA, J. L. Notas sobre a experiência e o saber de experiência. Rev. Bras. Educ. [on-line]. 2002, n.19, p. 20-28. ISSN 1413-2478.

CERTEAU, M. de. A invenção do cotidiano: artes do fazer. 16. ed. Petrópolis, RJ: Vozes, 2009.

CORDEIRO, L. Z; CORREA, J.; FORMIGOSA, M. M. Cibercultura e ensino de ciências: questões contextuais a partir da disciplina Tecnologia da Informação e Comunicação (tics) no curso de educação do campo ênfase, em ciências da natureza. Boletim Gepem (On-line), v. 75, p. 1-15, 2019.

ECHEVERRÍA, Rafael. Escritos sobre aprendizaje: recopilation. Buenos Aires: Granica, 2016. ESCOBAR, Arturo. Welcome to Cyberia: notes on the anthropology of cyberculture. Current Anthropology. V. 35, n. 3, 1994. 
FERRAÇO, Carlos Eduardo. Pesquisa com o cotidiano. Educ. Soc., Campinas, v. 28, n. 98, p. 73-95, jan./ abr. 2007.

GIMONET, J.C. Praticar e compreender a Pedagogia da Alternância dos CEFFAS. Petrópolis, RJ: Vozes, 2007.

GOHN, M.G. Educação não formal, participação da sociedade civil e estruturas colegiadas nas escolas.

Ensaio: aval, pol., publ. Educ., Rio de janeiro, v.14, n. 50, p. 27-38, 2006.

MACEDO R. S. A etnopesquisa crítica e multirreferencial nas ciências humanas e na educação.

Salvador: EDUFBA, 2000.

MACEDO, R. S.; Borba, S.; Barbosa, J. G. Jacques Ardoino e a Educação. Coleção Pensadores e Educação. Belo Horizonte: Autêntica, 2012.

MORÁN, J. Mudando a educação com metodologias ativas. Coleção Mídias Contemporâneas.

Convergências Midiáticas, Educação e Cidadania: aproximações jovens, v. 2, p. 15-33, 2015.

PASSOS E; KASTRUP, V; ESCÓSSIA, L. (Orgs.). Pistas do método da cartografia: pesquisa-intervenção e produção de subjetividade. Porto Alegre: Sulina, 2009.

PRETTO, N.; ASSIS, N. Cultura digital e educação: redes já. In: PRETTO, N.; SILVEIRA, A. (Orgs.) Além das redes de colaboração: internet, diversidade e tecnologias do poder. Salvador: EDUFBA, 2008.

SANTOS, E.; WEBER, A. Diários on-line, cibercultura e pesquisa-formação multirreferencial. In: LIMA, S. L. et al. (Org.). Didática e prática de ensino na relação com a escola. Fortaleza: EdUECE, 2015. Livro 1, p. 1775-1786. Disponivel em: <http://www.uece.br/endipe2014/ebooks/livro1/205-\%20 DI\%C3\%81RIOS\%200NLINE,\%20CIBERCULTURA\%20E\%20PESQUISA-FORMA\%C3\%87\%C3\%830\%20 MULTIRREFERENCIAL.pdf>. Acesso em: 23 jan. 2020.

SARR, F. Afrotopia. São Paulo: N - 1 Edições, 2019.

SEGATA, J.; RIFIOTIS, T. (Orgs.) Políticas etnográficas no campo da cibercultura. Brasília: ABA Publicações; Joinville: Editora Letradágua, 2016.

VALENTE, J. A. Blended learning e as mudanças no ensino superior: a proposta da sala de aula invertida. Educar em Revista, v. 4, p. 79-97, 2014. 